\title{
Factors associated with joint mobility in an adolescent population
}

\author{
A J SILMAN, S J DAY, AND D O HASKARD* \\ From the Department of Clinical Epidemiology, The London Hospital Medical College
}

SUMMARY Fixed torque devices were used to measure joint mobility at three sites in 364 adolescents including 39 families with at least two siblings. Increasing age and being male were associated with reduced laxity, and a strong effect of family was observed in the 39 sibling sets studied. The population included 47 Asians whose mobility was similar to that of the non-Asians, though the female/male difference was apparently greater in the former group. None of the above conclusions apply to index finger hyperextension, and it is apparent that genetic and constitutional factors only affect mobility at some sites. Such observations could lead to a review of current scoring systems for clinical hypermobility.

Key words: hypermobility syndrome, mitral valve prolapse, occurrence, genetics.

Mobility at individual joints probably follows a normal distribution, ${ }^{12}$ with hypermobile individuals representing the extreme. Training probably increases an individual's range of movement, ${ }^{3}$ though genetic factors are important in the aetiology of those with the hypermobility syndrome. ${ }^{45}$ In population studies women tend to have joints of greater laxity than men, ${ }^{1}$ but age has been found to have little influence except in early childhood and beyond middle age. ${ }^{67}$ There are also differences in joint mobility between ethnic groups, with those of Asian origin having greater mobility. ${ }^{8}$ There are little data on genetic influences on joint mobility in normal individuals.

We have recently applied fixed torque measuring devices $^{910}$ to the study of joint mobility at three sites in a population of adolescents and young adults. ${ }^{2}$ In that report it was found that mobility at each site followed a normal distribution, but an individual's mobility at one site could not predict mobility at the other two sites studied. This present account describes the effect of age, sex, racial and family factors in explaining the variance in joint mobility described in that paper.

\section{Subjects and methods}

Subjects were 364 individuals attending biology

Accepted for publication 29 August 1986.

Correspondence to $\mathrm{Dr}$ A J Silman, Department of Clinical Epidemiology, The London Hospital Medical College, London E1 1 BB.

*Present address: Department of Rheumatology, Guy's Hospital, London. classes at a local school and two polytechnics. The polytechnic classes were added to extend the age range of the sample. The school had recently become coeducational and this combined with the differential self selection of individuals to study biology resulted in there being only $97(26 \cdot 6 \%)$ female compared with $263(72 \cdot 3 \%)$ male students (in four cases the sex was not recorded). Ninety five per cent of all subjects were aged between 11 and 20 , though three were above 25 years. There were 47 children whose parents were either of Indian or Pakistani origin in the population studied; the remainder (excluding one with no record of ethnic origin) were European. In 39 instances there was more than one individual from the same family-37 sibling pairs and two trios.

Joint mobility was measured for the following movements: index finger hyperextension, forearm rotation, and lower limb rotation. The last two represent composite movements and thus reflect mobility at more than one joint. Measurements were undertaken using fixed torque measuring devices first described by Jobbins et al. ${ }^{9}$ The particular devices used in this study have low levels of both within and between observer variability as previously described, ${ }^{10}$ making them appropriate for use in epidemiological studies. The method of measurement in this population has been reported elsewhere. ${ }^{2}$ In each class three trained observers were used, one for each measurement. During the course of the study five individual observers were used. The constraint of timetabling resulted in some individuals not being tested for all three movements. 
210 Silman, Day, Haskard

Table 1 Effect of age on mobility

\begin{tabular}{|c|c|c|c|c|c|}
\hline Movement & $\begin{array}{l}\text { Number } \\
\text { tested }\end{array}$ & $\begin{array}{l}\text { Change } \\
\text { (degrees) } \\
\text { per year } \\
\text { of age }\end{array}$ & $S E^{*}$ & $\begin{array}{l}p \\
\text { Value }\end{array}$ & $\begin{array}{l}95 \% C I^{*} \\
\text { for change } \\
\text { (degrees) }\end{array}$ \\
\hline \multicolumn{5}{|l|}{ Index finger } & $-0.5, \quad 1 \cdot 1$ \\
\hline $\begin{array}{l}\text { Forearm rotation } \\
\text { Lower limb }\end{array}$ & 260 & $-1 \cdot 2$ & $0 \cdot 8$ & NS & $-2 \cdot 8, \quad 0 \cdot 4$ \\
\hline rotation & 277 & $-2 \cdot 4$ & $0 \cdot 8$ & $<0.01$ & $-4 \cdot 0,-0 \cdot 8$ \\
\hline
\end{tabular}

${ }^{*} \mathrm{SE}=$ standard error; $\mathrm{Cl}=$ confidence interval.

The observers used were manifestly aware of the subject's sex, ethnic origin, and approximate age but were blind to the results from other individuals in the same family.

The data were analysed by standard analysis of variance and covariance techniques using the computer program SAS. ${ }^{11}$ The effect of the four predictors studied-age, sex, ethnic group, and family — on joint mobility at each site was analysed. The results are presented after adjustment for the other three variables where analysis suggested such adjustment was appropriate.

\section{Results}

A small effect of age after adjustment for sex was observed on all three movements tested (Table 1). 뭉. Within the narrow age band studied there was negligible change in index finger hyperextension but $\stackrel{\vec{s}}{\overrightarrow{0}}$ decreases in both forearm and leg rotation of one and $\bar{O}$ two degrees per year respectively. Only the leg 흠 rotation was statistically significant and represents a $\bar{s}$ decline of the order of 20 degrees during the second decade of life against an overall mean of 75 degrees.

Women had greater mobility for both forearm and leg rotation (Table 2 ), the differences being $\vec{\circ}$ highly significant. Adjustment for age increased the differences slightly: 47 and 32 degrees for forearm and leg rotation respectively. Conversely, there was a greater mean index finger hyperextension in men, and the difference, though small, was statistically significant. Again age adjustment made no difference to the results.

Joint mobility at the sites studied was not appreciably different between the two ethnic groups studied (Table 3). The Asians had an increase in the $z$ mean finger hyperextension of five degrees, an increase in leg rotation of four degrees, and a $\stackrel{\rho}{د}$ decrease in forearm rotation of seven degrees, but $\vec{\bullet}$ the confidence intervals suggest these may not be $\infty$ real differences. There were too few Asian women ${ }^{11}$. for a useful comment to be made on the differences in the sex effect in the two racial groups. Both ethnic groups, however, showed the pattern described for the study population as a whole of a greater index

Table 2 Effect of sex on mobility

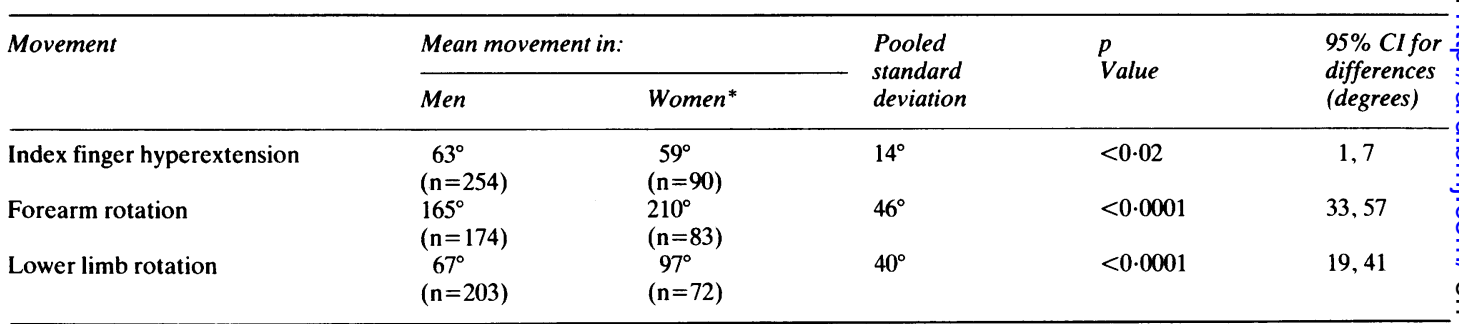

*The total numbers do not add up to the combined sex totals in Table 1 owing to missing data on four individuals. This discrepancy is noto the same for each of the movements as not all subjects were tested for each movement (see text).

Table 3 Joint mobility by racial group

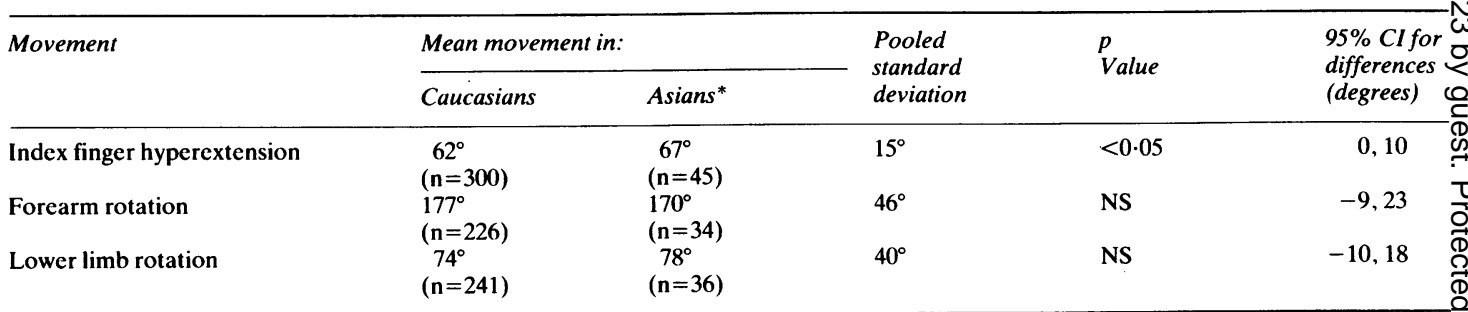

*There was one individual who had their index finger extension measured for whom no record of their race was available. 
Table 4 Variation in lower limb rotation: table of analysis of variance to describe the effect of sex and family

\begin{tabular}{lrccll}
\hline $\begin{array}{l}\text { Source of } \\
\text { variation }\end{array}$ & $\begin{array}{l}\text { Sums of } \\
\text { squares }\end{array}$ & $\begin{array}{l}\text { Degrees of } \\
\text { freedom }\end{array}$ & $\begin{array}{l}\text { Mean } \\
\text { squares }\end{array}$ & $\begin{array}{l}\text { Variance } \\
\text { ratio }\end{array}$ & $\begin{array}{l}p \\
\text { Value }\end{array}$ \\
\hline Sex & 3602 & 1 & 3602 & $5 \cdot 8$ & $<0 \cdot 025$ \\
Family & 61965 & 38 & 1631 & $2 \cdot 6$ & $<0 \cdot 01$ \\
Residual & 24644 & 40 & 616 & & \\
Total & 90211 & 79 & & & \\
\hline
\end{tabular}

finger hyperextension in men and greater forearm and lower limb rotation in women. In the Asians there was a male-female difference for forearm rotation of 93 degrees compared with 44 degrees in Caucasians, perhaps suggesting that the sex effect is more pronounced in the former group. Thus the ethnic difference in sex effect might not be consistent at all sites, but the numbers studied were small.

Finally, in the 39 sibships studied there was a strong effect of family on mobility, though, as with sex, there was no effect on index finger hyperextension. The results of the analysis of variance for lower limb rotation (Table 4) confirm that a significant proportion of the total variation is explained by that due to within family variation.

\section{Discussion}

The study population was peculiar insofar as it was selected to cover biology students and as a consequence had a disproportionately higher number of men, and thus did not represent a random sample of UK adolescents. It is perhaps unlikely that these students were selectively different in joint mobility compared with their colleagues opting for other subjects. Further, it is difficult to explain the between subgroup observations on the basis of differential selection in the sample studied. Thus it is unlikely that the greater mobility observed in women results from a selective inclusion of women with laxer joints and men with stiffer joints compared with the general population.

This study has therefore shown that within the age group studied mobility declines with age. This effect is less than that due to sex, with the observation of significantly greater mobility in women. These findings are thus consistent with the observation of others using standard goniometry. ${ }^{1}$ The Asian population studied living in the UK showed little difference from the indigenous population, though the possibility of a greater sex effect in the former group cannot be ruled out. The effect of family was as relevant as sex in determining mobility at the sites measured. These conclusions, however, apply only to forearm and lower limb rotation and not to index finger hyperextension. The index finger hyperextension was greater in men and unaffected by age or 'family'. Others have also failed to find increased finger mobility in women. ${ }^{12}$ In our previous report we had observed that an individual's mobility at the index finger is independent of his mobility at the other two sites. ${ }^{2}$ Thus the observation that the predictors studied in this respect varied in their effect on mobility depending on site is not surprising. Such observations are similar to those from a recent study of ballet dancers showing that spinal flexion is related to training but mobility at other sites is more related to genetic factors."

It would thus appear that at some sites joint mobility is related to constitutional factors, for which age, sex, ethnic background, and family may be markers, whereas at other sites such factors are not operative and mobility might be more related to use. Currently accepted scoring systems for defining clinical hypermobility syndromes ${ }^{+}$may, therefore, need to be reviewed in the light of the differences in influence of the aetiological factors on each of the various sites observed in this study. One problem in extrapolating from the present study is that at a single measurement session mobility in each joint site was assessed by a different observer. It is unlikely, however, that observer bias explains the results since a previous report shows low between observer variation with the devices used. ${ }^{10}$

The recognition of those with increased mobility is frequently only of academic interest, though the recently described association between mitral valve prolapse and hypermobility ${ }^{1.314}$ has encouraged greater interest in the subject. In this regard the observation from epidemiological studies that prolapse is commoner in women, declines in prevalence with age, and frequently has a strong family history ${ }^{15}$ is consistent with our data on forearm and lower limb rotation. Further, a hereditary tendency to joint mobility could partly explain a familial disposition to degenerative joint disease.

\section{References}

1 Fairbank J C T. Pynsent P B. Phillips H. Quantitative measurements of joint mobility in adolescents. Ann Rheum Dis 1984: 43: 288-94.

2 Silman A J. Haskard D O. Day S. The distribution of joint mobility in a normal population: results of the use of fixed torque measuring devices. Ann Rheum Dis 1986: 45: 27-30.

3 Grahame R. Jenkins J M. Joint hypermobility-asset or liability. Ann Rheum Dis 1972: 31: 109-11.

4 Beighton P. Horan F T. Dominant inheritance in familial generalised articular hypermobility. J Bone Joint Surg /Br/ 1970: 52: $145-7$ 
5 Klemp P. Stevens J E. Isaacs S. A hypermobility study in ballet dancers. J Rheumatol 1984; 11: 692-6.

6 Boone D C, Azen S P. Normal range of motion of joints in male subjects. J Bone Joint Surg /Am/ 1979; 61: 756-9.

7 Alexander R E, Battye C K. Goodwill C J, Walsh J B. The ankle and sub-talar joints. Clin Rheum Dis 1982; 8: 703-11.

8 Harris H. Joseph J. Variation in extension of the metacarpophalangeal and interphalangeal joints of the thumb. $J$ Bone Joint Surg 1948: 547-59.

9 Jobbins B, Bird H A. Wright V. A joint hyperextensometer for the quantification of joint laxity. Eng Med 1979; 8: 103-4.

10 Haskard D O, Silman A J. Measuring devices for studying joint mobility in the normal population. Eng Med 1985; 14: 75-78.
11 SAS Institute. SAS users guide. Cary: SAS Instutute Inc, 1982. "

12 Cantrell T, Fisher T. Small joints of the hands. Clin Rheum Dis 1982: 8: $545-57$.

13 Grahame R. Edwards J C. Pitcher D. Gabell A. Harvey W. A clinical and echocardiographic study of patients with the $\bar{\sigma}$ hypermobility syndrome. Ann Rheum Dis 1981: 40: 541-6.

14 Pitcher D, Grahame R. Mitral valve prolapse and joint $\underset{\mathbb{D}}{\mathbb{Q}}$ hypermobility: evidence for a systemic connective tissuc abnormality. Ann Rheum Dis 1982; 41: 352-4.

15 Savage D D, Garrison R J, Devereux R B, et al. Mitral valve prolapse in the general population. I Epidemiological features: the Framingham study. Am Heart $J$ 1983: 106: 571-5. 